\title{
Spatial spillover effect and driving forces of carbon emission intensity at the city level in China
}

\author{
WANG Shaojian, HUANG Yongyuan, ZHOU Yuquan \\ Guangdong Provincial Key Laboratory of Urbanization and Geo-simulation, School of Geography and Planning, \\ Sun Yat-sen University, Guangzhou 510275, China
}

\begin{abstract}
In this study, we adopt kernel density estimation, spatial autocorrelation, spatial Markov chain, and panel quantile regression methods to analyze spatial spillover effects and driving factors of carbon emission intensity in 283 Chinese cities from 1992 to 2013. The following results were obtained. (1) Nuclear density estimation shows that the overall average carbon intensity of cities in China has decreased, with differences gradually narrowing. (2) The spatial autocorrelation Moran's I index indicates significant spatial agglomeration of carbon emission intensity is gradually increasing; however, differences between regions have remained stable. (3) Spatial Markov chain analysis shows a Matthew effect in China's urban carbon emission intensity. In addition, low-intensity and high-intensity cities characteristically maintain their initial state during the transition period. Furthermore, there is a clear "Spatial Spillover" effect in urban carbon emission intensity and there is heterogeneity in the spillover effect in different regional contexts; that is, if a city is near a city with low carbon emission intensity, the carbon emission intensity of the first city has a higher probability of upward transfer, and vice versa. (4) Panel quantile results indicate that in cities with low carbon emission intensity, economic growth, technological progress, and appropriate population density play an important role in reducing emissions. In addition, foreign investment intensity and traffic emissions are the main factors that increase carbon emission intensity. In cities with high carbon intensity, population density is an important emission reduction factor, and technological progress has no significant effect. In contrast, industrial emissions, extensive capital investment, and urban land expansion are the main factors driving the increase in carbon intensity.
\end{abstract}

Keywords: Chinese cities; kernel density estimation; spatial autocorrelation; spatial spillover effect; spatial Markov chain; quantile regression panel model

\section{Introduction}

Although the proposal that greenhouse gases, especially carbon emissions, are the primary cause of climate change remains controversial, promoting an emission reduction plan to ad-

Received: 2018-04-07 Accepted: 2018-06-01

Foundation: National Natural Science Foundation of China, No.41601151; Natural Science Foundation of Guangdong Province, No.2016A030310149; Pearl River S\&T Nova Program of Guangzhou (201806010187)

Author: Wang Shaojian (1986-), Associate Professor, specialized in urban geography and regional development. E-mail: 1987wangshaojian@163.com 
dress the challenges posed by climate change is the consensus of mainstream scientific circles (Liu et al., 2008). In this context, China has achieved rapid and continuous economic growth after the reform and opening up, with the associated rapid advancement of urbanization and industrialization increasing demand for energy consumption (Wang et al., 2014a, 2014b). According to statistics released by the International Energy Agency (IEA, 2009), in 2007, China's total carbon emissions exceeded the United States and ranked first in the world. Facing international public opinion pressure, the Chinese government adopted the emission reduction task as binding in the medium and long-term plans for national economic and social development in 2009 (Wang et al., 2017), promising to reduce China's carbon emission intensity (CEI) by 40-45\% compared with 2005 by 2020 . However, the BP World Energy Statistical Yearbook (2017), released in 2017, shows that China's total carbon emissions are still rising, from $20.9 \%$ in 2005 to $27.5 \%$ in 2014 . For China, reducing the intensity of carbon emissions while maintaining sustained economic growth remains a big challenge (Wang et al., 2015; Wang et al., 2016a, 2016b). Therefore, research evaluating the spatio-temporal patterns and driving factors of CEI will be beneficial to further development of emission reduction measures.

CEI, as carbon emissions per unit of GDP, is a measure of the relationship between carbon emissions and economic development in a country or region. For developing countries, it is more practical to use CEI to quantify emission reduction targets compared to total carbon emissions or per capita carbon emissions (Jotzo and Pezzey, 2007). Many scholars have studied the issue of carbon emissions in the last decade with rich results, including measurement and decomposition, the characteristics of spatio-temporal patterns (including regional differences, spatial agglomeration, and spatial correlation), and driving factors of CEI (Zhao et al., 2018). The research scale varies from national, regional, and provincial to municipal units, although most have focused on the provincial level. In terms of research methods, scholars often use the Theil index, coefficient of variation, and spatial autocorrelation (the global Moran's I index and local G coefficient) to reveal regional differences and spatial correlations of CEI. For example, Sun et al. (2012) explored differences in CEI among China's provinces and regions (eastern, central, western, and northeastern) based on the Theil index. They found that China's inter-provincial CEI varies and the differences have gradually increased, but intra-regional differences are declining annually, and inter-provincial differences are primarily derived from regional differences. Zhao et al. (2011) divided the country into eight economic regions and used the Theil index and global Moran's I to explore the spatial evolution characteristics of regional CEI and also found a widening difference in regional CEI across the country caused by greater differences among regions, while intra-regional differences were small. In summary, there are significant differences in the CEI between provinces in China due to the variations in their geographical regions. However, few studies have focused on the city level. In addition, research regions are often divided according to habitual experience, such as central, eastern and western parts of China, the six economic zones, coastal areas, and interior land areas. In this regard, many studies have shown that barriers between regions have gradually decreased over time, and elements and products between adjacent cities and counties can move more freely ( $\mathrm{Li}$ et al., 2004), which has gradually narrowed the scale of spatial spillover effects. As a result, analyses at the provincial scale alone do not address the true situation in China (Pan, 2012). In addition, most economic geographers believe that cities are key to regional development 
and the main source of carbon emissions and building low-carbon cities will be the most important component of carbon emissions reduction (Gu et al., 2009; Zhang et al., 2014), which highlights the importance of CEI research at the city level. Based on the limitations of previous research, this study evaluated spatial spillover effects and driving factors of CEI in 283 cities across China based on the city level. We further explain the spatial characteristic of CEI and explore its influencing factors.

Many scholars have introduced convergence theory and methods to conduct research on spatial and temporal characteristics of carbon emissions (Xu, 2010; Lin and Huang, 2011; Pettersson et al., 2014; Wu and Guo, 2016). Because the graphical features of the kernel density estimation method can reflect data evolution trends, Ma et al. (2015) and Zhao et al. (2018) used it to describe carbon emission performance and intensity over the years. At the same time, Zhao et al. (2017) introduced the Markov state transition probability matrix to reflect the internal dynamic evolution trend of CEI. However, the above method only explores changes in the region, ignoring the proximity and spatial characteristics of carbon emissions. Considering these two important characteristics, this study adds spatial lag conditions to the traditional Markov chain method and uses the spatial Markov chain transition probability matrix to dynamically reveal the spatial and temporal evolution process of CEI in cities. Therefore, we address the lack of regional background evaluation in the existing literature.

In terms of driving factors, scholars have primarily used exponential decomposition, structural decomposition, cointegration test, Granger causality test and regression empirical analysis based on panel data. Cheng et al. (2013) used spatial econometric models and found that energy structure, industrial structure, and urbanization rate play an important role in the evolution of CEI. Yan et al. (2016) used the Sharpe value decomposition method to decompose and analyze the CEI for 29 provinces in China and found that the contribution rate from economic development to the CEI difference is the largest and increases gradually over time. Zhou and Wang (2014) used the panel regression model to explore the driving factors of CEI and found that capital per capita, urbanization, marketization, and industrial structure are the main factors of the difference. In contrast, scholars have mainly discussed the influencing factors based on scale, structural, and technical effects. In addition, according to the International Energy Agency (IEA), in 2007, the global transportation sector emitted 66.23 tons of carbon dioxide, accounting for $23 \%$ of all energy activities. Therefore, transportation is one of the most important factors affecting carbon emissions. According to estimates by Cai et al. (2011) and others, China's road transport accounted for $86.32 \%$ of transportation emissions in 2007, which is the main source of carbon emissions from transportation. Current research on the relationship between transportation and carbon emissions mainly includes the influencing factors of transportation carbon emissions (Zhang and Zeng, 2013), the impact of the transportation sector (Glaeser and Kahn, 2010), and transportation infrastructure (Xie et al., 2017) on carbon emissions. Based on existing research results (Li et al., 2018; Su et al., 2018), this study selected economic development level, population density, industrial structure, capital investment intensity, foreign capital intensity, land urbanization, and road density as driving factors, combining the quantile sorting technique in the Markov method and quantile regression method to explore the driving factors of urban CEI.

For these analyses, 283 cities in China were used as the research unit. First, the spatial autocorrelation method was used to test the spatial agglomeration of urban carbon emissions. 
Then, we used the spatial Markov chain to analyze the evolution of regional contexts and urban CEI and reveal the spatial spillover effects of urban CEI under different regional contexts. Finally, we used the panel quantile regression model to explore the driving factors affecting urban CEI under different regional backgrounds. The research design has three advantages. (1) The research scale is further reduced to the city level, which is in better agreement with the reality of spatial spillover effects. (2) Using the spatial Markov chain is effective at revealing the heterogeneity of spatial spillover effects for cities in different regional contexts. (3) Using quantile regression to explore the driving factors under different conditions of CEI level provides a basis for emission reduction strategies in cities with different CEI stages.

\section{Data and methodologies}

\subsection{Research area and data sources}

As the most concentrated area of human social and economic activities, cities have become the most concentrated carbon emissions regions (Gu et al., 2009). Therefore, many countries and regions regard cities as an important space carrier for local emission reduction measures (Cong et al., 2014) and promote building low-carbon cities. We use cities as the basic unit of research and define the urban scope using the administrative boundaries of each city in 2013. Due to statistics missing for some cities, 283 cities covering 34 provincial administrative units were studied, but Hong Kong, Macao, and Taiwan were excluded. The main variable studied was the CEI with a study period from 1992 to 2013.

In terms of data sources, due to the lack of detailed energy data for China's cities, it is impossible to measure China's urban carbon emissions comprehensively. To analyze the spatial spillover effects and driving factors of China's urban CEI, urban carbon emissions data were compiled from published literature (Wang and Liu, 2017). City socio-economic data were obtained from China's Urban Statistical Yearbook, China's Regional Economic Statistical Yearbook, and the statistical yearbooks from various provinces, regions, and counties, Statistical Bulletin of National Economic and social development, and government work reports.

\subsection{Research on spatial spillover effects based on spatial Markov chain}

\subsubsection{Markov chain}

The traditional Markov chain is a discrete event stochastic process in mathematics, which is discrete in time and state, emphasizing that the historical state is not related to the future state. Because many geomorphic phenomena have no post-effects, the Markov chain is widely used in geography $(\mathrm{Xu}, 1996)$. Therefore, the Markov chain method is appropriate for evaluating CEI because urban CEI has no post-effects. Specifically, the Markov chain method discretizes the urban CEI at different time periods and divides a city's CEI into $k$ types according to quantiles. Then, the evolution process of urban CEI can be approximately regraded as a Markov process by calculating various types of probability distributions and its transition probabilities. In general, the urban carbon emission state type at time $t$ is represented by a $1 \times k$ state probability vector $E_{t}=E_{1, t}, E_{2, t}, \cdots, E_{k, t}$. The state transition process for urban CEI over the entire study period can be represented by a $k \times k$ Markov transition prob- 
ability, which is the matrix M. This study is based on the principle that each type of city has a similar CEI and divides the city's CEI into four types according to quartiles $(0.25 / 0.5 / 0.75)$, which are represented by $k=1,2,3$, and 4 , respectively. A greater value of $k$ is related to a greater intensity of carbon emissions. The state type from high intensity to low intensity is defined as an upward shift and from low intensity to high intensity is defined as a downward shift. $m_{i j}$ represents the probability value of the region belonging to type $i$ at time $t$, which transitions to type $j$ at time $t+1$, and is estimated by the following equation:

$$
m_{i j}=\frac{n_{i j}}{n_{i}}
$$

where $n_{i j}$ represents the sum of the regions belonging to type $i$ at time $t$ that experiences transitions to type $j$ at time $t+1$ during the entire study period, and $n_{i}$ is the sum of regions belonging to type $i$ in all years of transition in the study period.

\subsubsection{Spatial Markov chain}

Regional connection and interaction processes create spatial spillover effects between regions, which reveal the spatial spillover effect between regions and are important in understanding regional development. The spatial Markov chain can better describe such regional spatial spillover patterns, and is essentially a product of the traditional Markov chain that introduces the concept of "space lag" (Gallo, 2004). From a geospatial perspective, regional phenomena are not isolated in geospatial space. Regional phenomena are always affected by the condition of geographically adjacent areas, that is, the state of regional context will have an impact on the state transition process of the region. The spatial Markov chain method expresses the regional context by introducing a "space lag", thus addressing the deficiencies of the traditional Markov chain that ignored spatiality (Chen and Zhu, 2013). The spatial Markov chain transition probability matrix is based on the spatial lag type of region $a$ at time $t$ and decomposes the traditional Markov chain into $\mathrm{k} k \times k$ conditional transition probability matrices. In the $k$ th conditional matrix, $m_{k i j}$ is the probability that a certain region $a$ will shift from state type $i$ at time $t$ to the state type $j$ at time $t+1$ under the condition that the spatial lag type is $k$. The spatial lag value for region $a$ is the weighted average of the attribute values for a spatial neighboring area. The specific equation is as follows:

$$
\operatorname{Lag}_{a}=\sum Y_{b} W_{a b}
$$

where the spatial weight matrix $W_{a b}$ represents the spatial relationship between region $a$ and region $b$, and the subjacency principle is used to define the spatial relationship in this paper, due to missing statistics, for cities without neighboring cities, we define the closest city as the neighboring city. $Y_{b}$ represents the attribute value of region $b$, and $\operatorname{Lag}_{a}$ is the spatial lag value for region $a$, indicating the neighborhood state of region $a$.

By comparing the elements in the Markov transition probability matrix and spatial Markov transition probability matrix, the importance of the regional background to the regional transition can be judged.

\subsection{Research on the driving factors based on quantile regression model}

Most regression models have been developed using the classical least squares method, focusing on the influence that the independent variable $x$ has on the conditional expectation $\mathrm{E}(y \mid x)$ of dependent variable $y$, which is essentially the mean regression and depicts the 
concentrated trend. However, the distribution of most data does not meet the classical assumption of the least squares method, and the conditional expectation $E(y \mid x)$ poorly reflects the whole conditional distribution(Chen, 2010). To resolve this flaw, Koenker and Bassett (1978) proposed the "Quantile Regression". The quantile regression characterizes the regression of the dependent variable using different independent variables quantiles, and the results can cover the influence of independent variables on the overall conditional distribution. In addition, this method uses the weighted average of the absolute values of the residuals as the objective function of minimization, so the estimation results are not affected by extreme values and are more stable than the least squares method. In the quantile regression, the $\tau$ quantile function $Q(\tau)$ of the explained variable $y$ is defined as:

$$
Q(\tau)=\inf \{y: F(y) \geqslant \tau\} \quad(0<\tau<1)
$$

where $\tau$ represents the percentage of data below the regression line compared to the total data; therefore, the distribution of $y$ is divided into two parts according to $\tau$, the proportion less than quantile $Q(\tau)$ is $\tau$, and the proportion greater than quantile $Q(\tau)$ is $(1-\tau)$.

For panel data, the general model is:

$$
y_{i t}=x_{i t}{ }^{T} \beta_{i}+\alpha_{i}+u_{i t} \quad(i=1,2, \cdots \cdots, K ; t=i=1,2, \cdots \cdots, T)
$$

where $i$ denotes different individuals, $t$ denotes the time of sample observation, $x_{i t}$ denotes the $k \times 1$-dimensional independent variable of the $i$-th individual in $t$ period, $u$ denotes a random error term vector, $\beta_{i}$ denotes an unknown coefficient of $k \times 1$-dimension, and $\alpha_{i}$ represents the individual effect of the $i$-th individual. The conditional quantile function of panel quantile regression parameter estimation is:

$$
Q_{y_{i t}}\left(\tau \mid x_{i t}, \alpha_{i}\right)=x_{i t}{ }^{T} \beta\left(\tau_{q}\right)+\alpha_{i}
$$

where $\tau \in(0,1)$, and when $\tau$ takes different values, solving the weighted absolute residual minimization results in the parameter estimator at different quantile points. Parameter $\beta$ is generally solved from the following equation:

$$
\hat{\beta}=\operatorname{argmin}_{\alpha, \beta} \sum_{q=1}^{Q} \sum_{t=1}^{T} \sum_{i=1}^{N} w_{k} \rho_{\tau}\left(y_{i t}-x_{i t}^{T} \beta\left(\tau_{q}\right) x_{i t}-\alpha_{i}\right)
$$

where $\rho_{\tau}(u)$ is a piecewise linear quantile loss function, and the specific expressions are:

$$
\rho_{\tau}(u)= \begin{cases}u \cdot(\tau-1), & u<0 \\ u \cdot \tau, & u \geqslant 0\end{cases}
$$

In response to various problems in panel quantile estimation methods (Luo and Tian, 2010), Koenker proposed a penalty effect quantile regression method for fixed effects. The method appropriately adjusts the individual effect by adding the penalty term $P(\alpha)=\sum_{i=1}^{n}\left|\alpha_{i}\right| \mid$ with the adjustment parameter $\lambda$ to effectively reduce the variance caused by the estimation $\alpha_{i}$ (Koenker, 2004). After adding the penalty term, the coefficient of the explanatory variable at the quantile can be obtained by solving the minimization problem using the following equation:

$$
\min \sum_{k=1}^{q} \sum_{t=1}^{T} \sum_{i=1}^{N} w_{k} \rho_{\tau k}\left(y_{i t}-x_{i t}^{T} \beta\left(\tau_{q}\right) x_{i t}-\alpha_{i}\right)+\lambda \sum_{i=1}^{N}\left|\alpha_{i}\right|
$$

where $w_{k}$ is the weight coefficient used to control the degree of influence on the estimation 
coefficients of the $q$ quantiles.

The factors affecting the intensity of carbon emissions have been explored in the published literature. The improved STIRPAT model based on the IPAT model proposes that the environmental pressure caused by human activities is mainly affected by population (P), affluence (A), and technological progress ( $\mathrm{T}$ ) and establishes a stochastic model between these three factors and the environmental impact (I) (York et al., 2003). The STIRPAT model is widely used in China to study various environmental impact indicators, such as carbon emissions, air pollution, and energy consumption. In recent years, many scholars have expanded the STIRPAT model. In addition to population, affluence, and technology, influencing factors include urbanization, economic growth, foreign trade, and industrial structure (Jiao and Chen, 2012). In addition, the hypothesis of the environmental Kuznets curve can be verified by adding a quadratic term or polynomial of wealth to the model. Based on the STIRPAT model and relevant CEI research results, this study analyzed the impact of human factors, such as affluence, population, industrial structure, foreign investment, urbanization, and road traffic on CEI (Table 1). Furthermore, we added the quadratic term (SA) for wealth to verify the environmental Kuznets curve hypothesis between wealth and environmental impact. It should be noted that, considering that government behavior values land urbanization, this study used land urbanization indicators to measure urbanization (Dong et al., 2018). CEI, urban affluence, population density, urbanization, and road density were placed logarithmically into the model.

Table 1 Main variables used in the applied model

\begin{tabular}{|c|c|c|c|}
\hline Type & Name & Units & Explanation \\
\hline $\begin{array}{l}\text { Explained } \\
\text { variable }\end{array}$ & $\begin{array}{l}\text { Carbon Emission Inten- } \\
\text { sity }(\mathrm{CEI})\end{array}$ & Tons $/ 10,000$ yuan & Total urban carbon emissions / GDP \\
\hline \multirow{8}{*}{$\begin{array}{l}\text { Explanatory } \\
\text { variables }\end{array}$} & Affluence (A) & yuan & Per capita GDP \\
\hline & Population (P) & $\left(\right.$ person $\left./ \mathrm{km}^{2}\right)$ & Total population / city area \\
\hline & Industry Structure (IS) & $\%$ & Second industry added value / GDP \\
\hline & Investment Intensity $(\mathrm{CI})$ & $\%$ & Total fixed assets investment / GDP \\
\hline & $\begin{array}{l}\text { Foreign Direct Invest- } \\
\text { ment (FDI) }\end{array}$ & $\begin{array}{l}10,000 \text { dollars / } \\
10,000 \text { yuan }\end{array}$ & Actual use of foreign capital / GDP \\
\hline & Technology progress $(\mathrm{T})$ & $\begin{array}{l}10,000 \text { yuan / ton of } \\
\text { standard coal }\end{array}$ & $\begin{array}{l}\text { Reciprocal of energy intensity (Total } \\
\text { energy consumption / GDP) }\end{array}$ \\
\hline & Land urbanization (UB) & $\%$ & Road $500 \mathrm{~m}$ buffer area / city area \\
\hline & Road Density (RD) & $\mathrm{km} / 100 \mathrm{~km}^{2}$ & Kilometer mileage / city area \\
\hline
\end{tabular}

In the model, for the null hypothesis " $\mathrm{H}_{0}$ : all $\mathrm{ui}=0$ " in the fixed effect panel model and $\mathrm{F}(282,5935)=21.41$ with a $p$ value is 0.0000 ; therefore, the null hypothesis was rejected. Using the LSDV method for further investigation, most individual dummy variables were found significant ( $p=0.0000$ ), so the null hypothesis that "all individual dummy variables are 0 " could be rejected; that is, the model should not adopt the mixed regression model. Next, Prob $>$ chi $2=0.0000$ was obtained using the Hausman test, which indicated that the model should use the fixed effect model. Therefore, the fixed-effect penalty quantile regression model was used to make estimates, and the $\mathrm{R}$ program package rqpd provided by Koenker was used to perform the calculation. The set estimation method was used to solve it, and the standard error was obtained through the bootstrap method (Koenker, 2004). 


\section{Empirical results and analysis}

\subsection{Time series and spatial correlation analysis of urban CEI}

Before analyzing the spatial spillover effects and influencing factors, the time series and spatial correlation of urban CEI were analyzed. Figure 1 shows the spatial distribution of
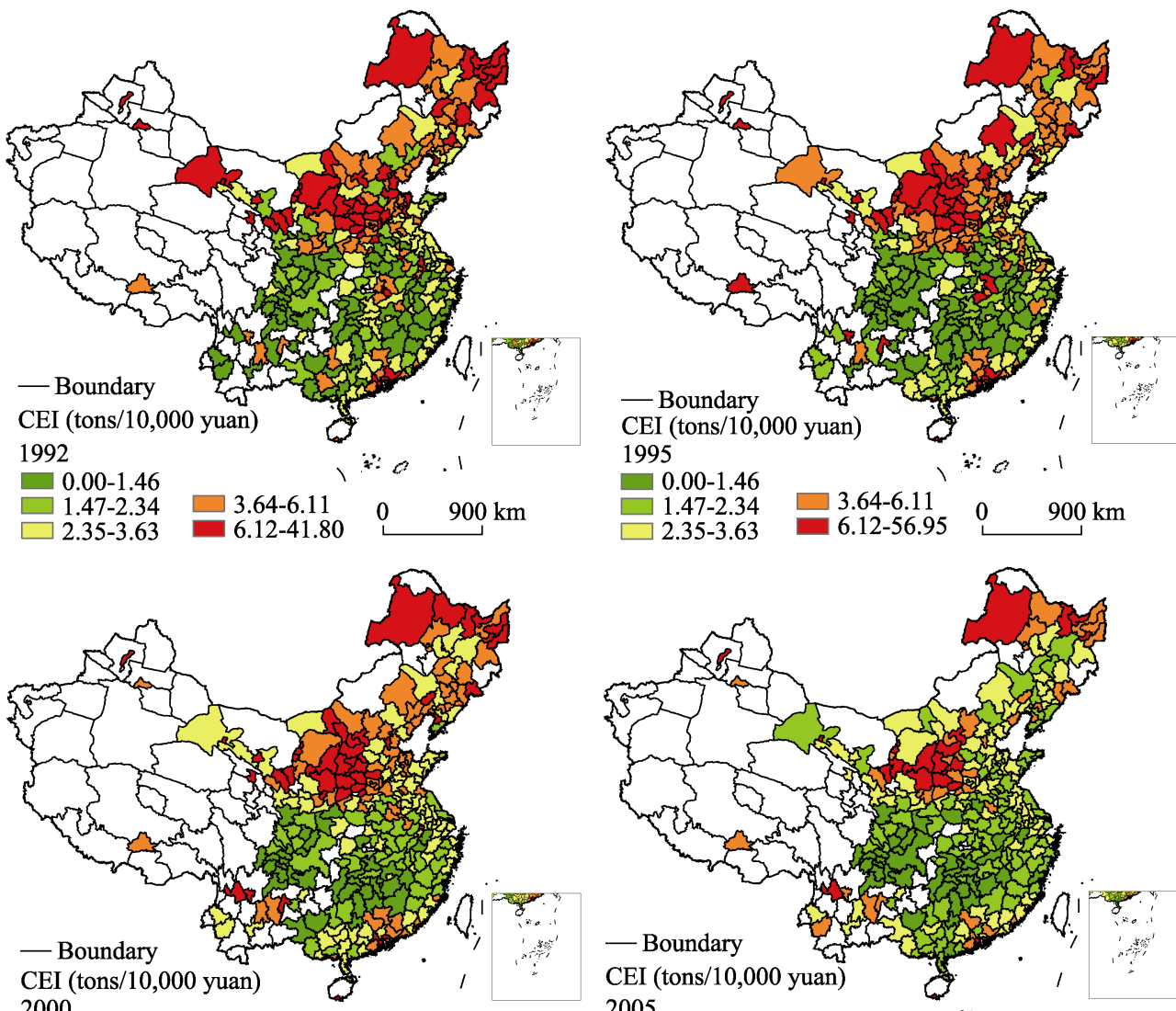
2000

0.33-1.46

$\square 1.47-2.34$

$\square 2.35-3.63$

\section{$\square$ 3.64-6.11}

$\because 0.1$

\section{$0 \quad 900 \mathrm{~km}$}

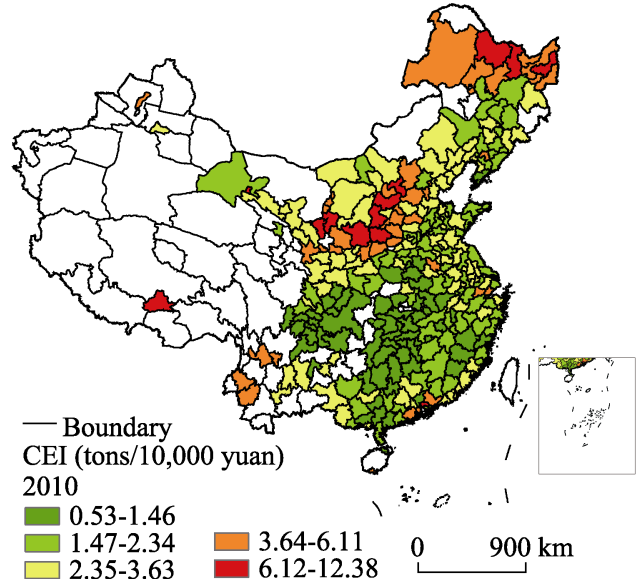

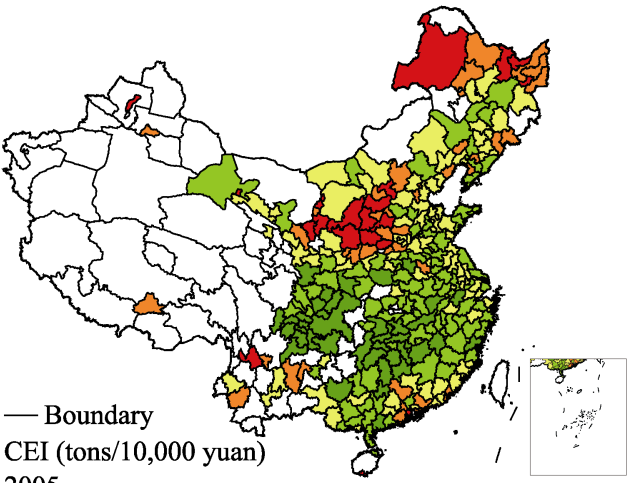
2005

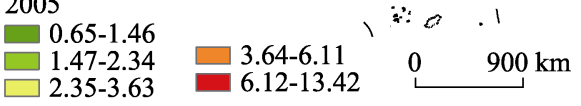

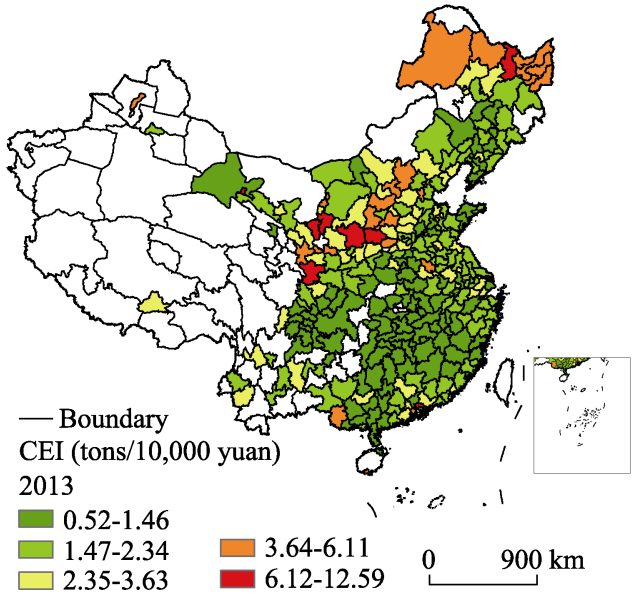

Figure 1 CEI spatial patterns at the city level in China (1992-2013) 
CEI in Chinese cities from 1992 to 2013. As shown, regions with higher CEI in 1992 were mainly concentrated in Heilongjiang, Jilin, Inner Mongolia, Ningxia, Shanxi, Shaanxi, Hebei, and Henan Provinces and the Pearl River Delta region. In contrast, by 2013, high CEI regions were mainly concentrated in Heilongjiang, Ningxia, and Shanxi Provinces. This distribution indicates that the overall CEI of Chinese cities has a downward trend, with particular prominence in the central, southern, and eastern regions.

Figure 2 is a box-plot of urban CEI showing that during the 22-year study period, the average CEI of urban cities in China gradually decreased with differences between city shrinking and converging. To further understand the distribution of urban CEI, this study selected the four years, 1992, 2000, 2005, and 2013, for further kernel density estimates (Figure 3). The overall trend in urban CEI changed; the kernel density curve is a transition from "squat" to "high-thin" and the peak shifted to the left. This shows that both the overall intensity and overall gap in urban CEI decreased, indicating that the government's carbon emission reduction measures have been effective. From the fluctuations at the end of the kernel density curve, between 2000 and 2013, numerical difference in cities with higher CEI gradually increased. This observation indicates that while the urban CEI decreased overall, a small part of the high intensity region has continued to miss the emission reduction target, and the gap with other cities increased.

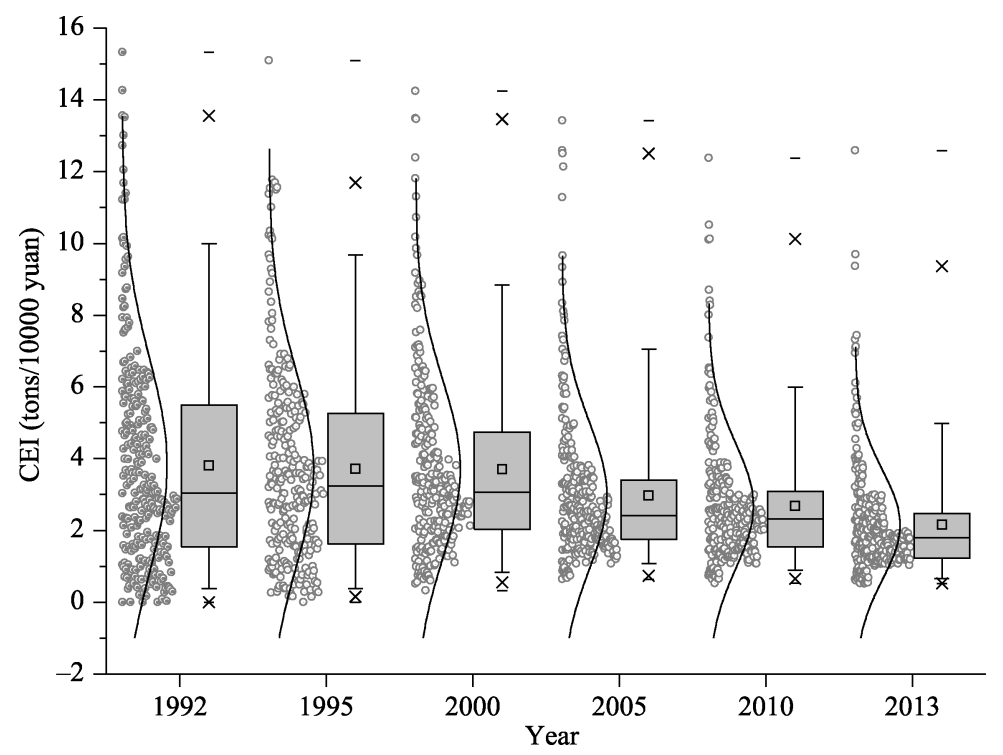

Figure 2 Box-plot of CEI at the city level in China

The box-plot and kernel density estimation methods only analyze the trend and distribution of urban CEI in the time dimension but cannot reflect the spatial characteristics of CEI. Therefore, the global Moran's I index was adopted to portray the spatial characteristics of CEI of Chinese cities and test the spatial correlation. Table 2 shows the global Moran's I index annual changes during the entire study period. All the years pass the test at the $1 \%$ significance level, indicating that urban CEI shows significant spatial clustering and positive spatial correlations in spatial distribution. Between 1992 and 2013, the overall Moran's I index showed a weak upward trend with fluctuations that gradually decreased. This observation indicates that the spatial agglomeration of urban CEI gradually increased, and the en- 
ergy utilization efficiency and technical level between adjacent cities had a certain spillover effect. Furthermore, the exchange and cooperation between cities and regions was generally stable while the level of spatial agglomeration decreased.

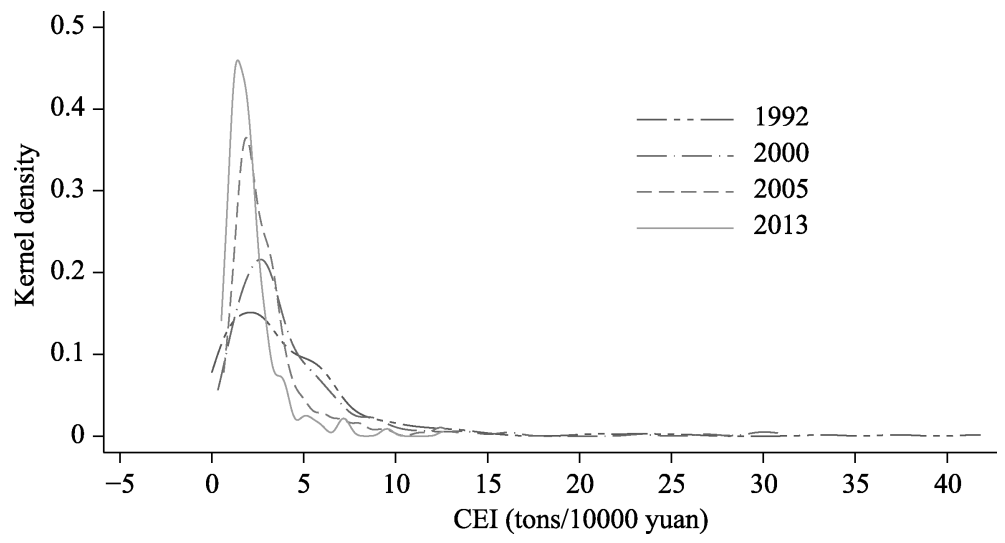

Figure 3 Kernel density estimates of CEI at the city level in China

Table 2 Moran's I for CEI at the city level in China (1992-2013)

\begin{tabular}{ccc||ccc}
\hline Year & Moran's I & Z value & Year & Moran's I & Z value \\
\hline 1992 & 0.359 & $8.717 * *$ & 2003 & 0.434 & $11.018 * *$ \\
1993 & 0.416 & $10.459^{* *}$ & 2004 & 0.435 & $11.903 * *$ \\
1994 & 0.336 & $8.807 * *$ & 2005 & 0.498 & $11.564 * *$ \\
1995 & 0.325 & $8.653 * *$ & 2006 & 0.478 & $11.003 * *$ \\
1996 & 0.292 & $7.565 * *$ & 2007 & 0.464 & $12.150 * *$ \\
1997 & 0.460 & $11.741 * *$ & 2008 & 0.443 & $11.124 * *$ \\
1998 & 0.316 & $8.143 * *$ & 2009 & 0.489 & $10.880 * *$ \\
1999 & 0.431 & $11.005 * *$ & 2010 & 0.448 & $10.599 * *$ \\
2000 & 0.411 & $10.504 * *$ & 2011 & 0.435 & $9.534 * *$ \\
2001 & 0.414 & $10.453 * *$ & 2012 & 0.428 & $11.903 * *$ \\
2002 & 0.417 & $10.516 * *$ & 2013 & 0.380 & $11.564 * *$ \\
\hline
\end{tabular}

Note: $*$ indicates significant at the $5 \%$ level, and ** indicates significant at the $1 \%$ level

\subsection{Analysis of spatial spillover effects of urban CEI}

Urban CEI is divided into four types: low intensity, relatively low intensity, relatively high intensity, and high intensity, corresponding to $\mathrm{k}=1,2,3$, and 4, respectively.

Figure 4 shows the spatial distribution of CEI in Chinese cities during the entire study period. The upward transfer of cities accounted for $57.95 \%$, the downward transfer of cities accounted for $13.07 \%$, and cities that remained stable accounted for $28.98 \%$ of the total number of cities. From the perspective of spatial distribution, the areas of upward transfer were mainly concentrated in northeastern and central China as well as provincial areas of Inner Mongolia, Shandong, and Guangdong. The downward transfer areas were concentrated in Guangxi, Yunnan, Shanxi, Ningxia, and southern Gansu Provinces, presenting a strong geographical agglomeration.

Table 3 shows the Markov transition probability matrix for the type of CEI in China. From the traditional Markov probability matrix, four important observations can be made. 


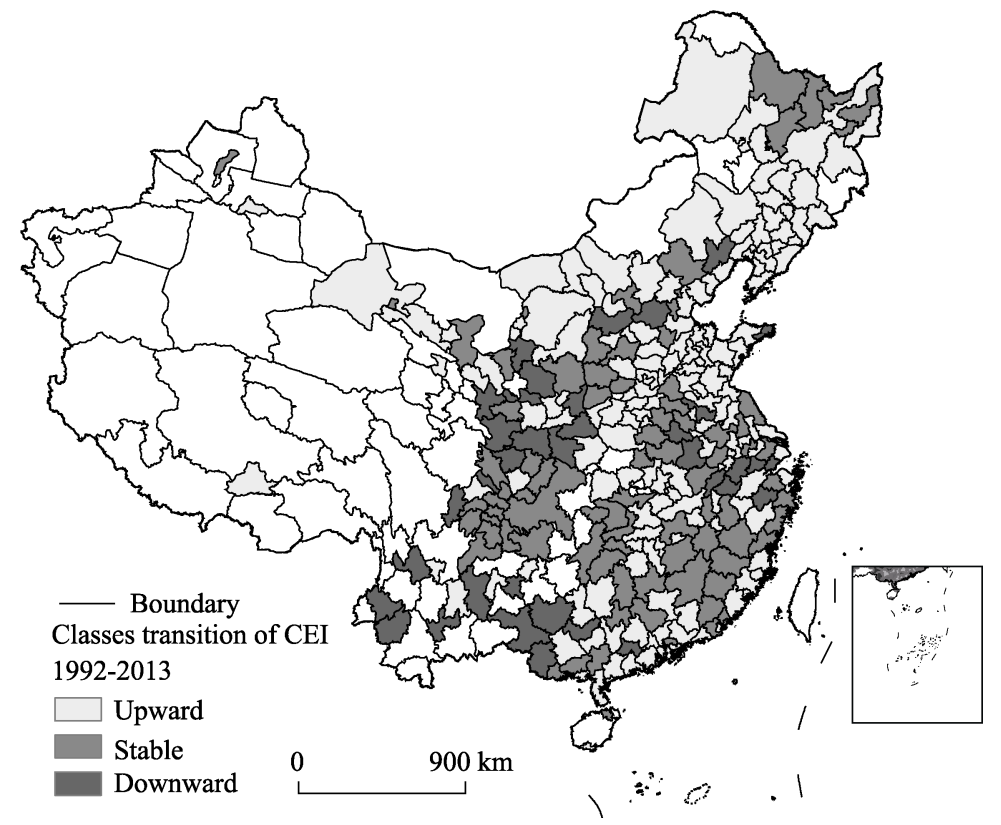

Figure 4 Spatial patterns of CEI changes in intensity types at the city level in China (1992-2013)

Table 3 Markov matrix for CEI classes at the city level in China (1992-2013)

\begin{tabular}{cccccc}
\hline $\mathrm{t} / \mathrm{t}+1$ & $\mathrm{n}$ & 1 & 2 & 3 & 4 \\
\hline 1 & 1439 & 0.8965 & 0.0980 & 0.0056 & 0 \\
2 & 1457 & 0.1290 & 0.7714 & 0.0954 & 0.0041 \\
3 & 1512 & 0.0013 & 0.1713 & 0.7798 & 0.0476 \\
4 & 1535 & 0.0020 & 0.0007 & 0.1094 & 0.8879 \\
\hline
\end{tabular}

(1) The probability values on the diagonal of the probability matrix are larger than the probability values of the non-diagonal. The lowest value is $77.98 \%$, and the highest value is $89.65 \%$; that is, throughout the study period, the minimum probability of maintaining the original state is $77.98 \%$, which indicates that the city's CEI type has strong stability.

(2) On the diagonal, the stability of the relatively low intensity and relatively high intensity in the middle $(77.14 \%, 77.98 \%)$ is significantly lower than the low and high intensity types at both ends $(89.65 \%, 88.79 \%)$. From the probability values on both sides of the diagonal, the probability of the two types of upward transfer in the middle $(12.9 \%, 17.13 \%)$ is greater than the probability of downward transfer in the middle $(9.54 \%, 4.76 \%)$, which indicates that the relatively low intensity and relatively high intensity types show good momentum for upward transfer.

(3) There is a "Matthew effect" in the intensity of urban carbon emissions. In the type transfer process for consecutive years, the probability of the region maintaining low intensity is $89.65 \%$, and the probability of a downward transfer is only $10.35 \%$, which indicates that there is a convergence of the time dimension in the region with high carbon emission efficiency. The probability of maintaining an initial high-intensity type is $88.79 \%$, and the probability of upward transfer is only $11.21 \%$, indicating that the region may fall into the path of resource dependence and path locking, and it will be difficult to achieve energy efficiency.

(4) The non-diagonal and non-diagonal sides have a small probability value, and the 
maximum value is only $0.54 \%$. Therefore, achieving technological progress and improving carbon emission efficiency is a continuous and gradual process. It is difficult to achieve rapid development in a short period of time, but at the same time, rapid development is not entirely impossible.

China's urban CEI is not independent of geography. City CEI is often affected by regional location, with strong spatial agglomeration and spatial interaction effects (Lin and Huang, 2011; Wang et al., 2013). Concurrently, knowledge and technology spillovers have regional characteristics, and the spillover intensity and spatial distance attenuation have exponential function patterns (Wang et al., 2003). Figure 5 is a spatial distribution diagram of urban CEI type transfer after joining the urban neighborhood state. As shown, regions where the regional and neighborhood state types are an upward transition mainly concentrated in the northeastern and central China, as well as Shandong and Guangdong. The areas transferring downwards are mainly distributed at the junction of Shaanxi, Gansu, and Sichuan provinces, which shows clear geographical agglomeration.

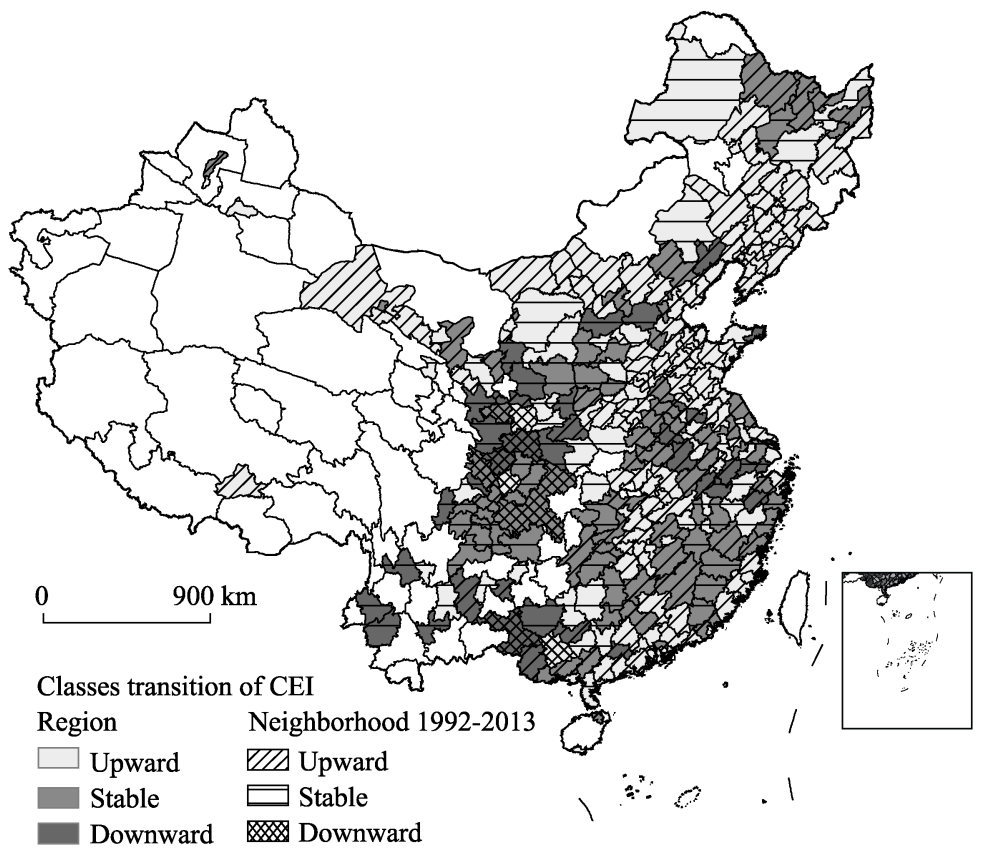

Figure 5 Spatial patterns of CEI class transition for city units also showing neighborhood transitions in China (1992-2013)

The spatial Markov chain method can discern the influence of different neighborhood types on the probability of urban CEI class transition. Based on the traditional Markov transition probability matrix, the neighborhood type is added to obtain the spatial Markov transition probability matrix (Table 4). Assuming that the regional background (neighborhood type of the region) is not important for the transfer of the region, then the transfer probability matrix under different regional backgrounds should be equal and the corresponding elements in the traditional Markov transfer probability matrix should be equal. Comparing Table 3 and Table 4, we make four observations.

First, this assumption is not true. Based on different regional background conditions, the state transition of the region shows a large difference. Therefore, the regional background has 
a significant impact on the state transition of the region.

Table 4 Spatial Markov matrix for CEI classes at the city level in China (1992-2013)

\begin{tabular}{|c|c|c|c|c|c|c|}
\hline Spatial Lag & $\mathrm{t} / \mathrm{t}+1$ & $\mathrm{n}$ & 1 & 2 & 3 & 4 \\
\hline \multirow{4}{*}{1} & 1 & 659 & 0.9408 & 0.0561 & 0.0030 & 0 \\
\hline & 2 & 357 & 0.1345 & 0.7703 & 0.0924 & 0.0028 \\
\hline & 3 & 257 & 0.0039 & 0.2257 & 0.7237 & 0.0467 \\
\hline & 4 & 176 & 0 & 0 & 0.1364 & 0.8636 \\
\hline \multirow{4}{*}{2} & 1 & 478 & 0.8766 & 0.1192 & 0.0042 & 0 \\
\hline & 2 & 467 & 0.1370 & 0.7687 & 0.0878 & 0.0064 \\
\hline & 3 & 314 & 0 & 0.2070 & 0.7516 & 0.0414 \\
\hline & 4 & 204 & 0.0098 & 0.0049 & 0.1422 & 0.8431 \\
\hline \multirow{4}{*}{3} & 1 & 244 & 0.8361 & 0.1516 & 0.0123 & 0 \\
\hline & 2 & 462 & 0.1364 & 0.7727 & 0.0887 & 0.0022 \\
\hline & 3 & 483 & 0.0021 & 0.1843 & 0.7723 & 0.0414 \\
\hline & 4 & 313 & 0.0032 & 0 & 0.1374 & 0.8594 \\
\hline \multirow{4}{*}{4} & 1 & 58 & 0.8103 & 0.1724 & 0.0172 & 0 \\
\hline & 2 & 171 & 0.0760 & 0.7778 & 0.1404 & 0.0058 \\
\hline & 3 & 458 & 0 & 0.1026 & 0.8384 & 0.0590 \\
\hline & 4 & 842 & 0 & 0 & 0.0855 & 0.9145 \\
\hline
\end{tabular}

Second, different neighborhood types have varying influences on regional state transitions. Generally speaking, if a region is adjacent to a region with low CEI, the probability of its CEI transferring upward will increase and transferring downward will decrease, and the neighbor will play a positive role in the regional state. If a region is adjacent to a region with high CEI, the probability of the CEI transferring upward will decrease and transferring downward will increase, and the neighbors will have a negative effect on the regional state. For example, for a region with high CEI, the probability of upward transfer is $11.21 \%$, and in the low CEI background context, the probability of upward transfer increases to $13.64 \%$. In the context of high intensity regions, the probability of an upward transfer is reduced to $8.55 \%$. For regions with low CEI, the probability of downward transfer is $10.35 \%$, when in the low CEI background context, the probability of downward transfer is reduced to $5.92 \%$, while in the context of high intensity regions, the probability of its downward transfer increased to $18.97 \%$.

Third, regional state types are affected differently by the regional background. For regions with lower CEI, when the neighborhood state types are 1,2, and 3, the probabilities of upward and downward transfer are similar, about $13 \%$ and $9 \%$. However, when there is an adjacent region with high CEI, the probability of upward transfer decreases to $7.6 \%$ and downward transfer increases to $14.62 \%$. This observation indicates that areas with low CEI are more sensitive to neighbors with high CEI and are more easily negatively affected.

Fourth, from a dynamic perspective for the whole study period, $50.9 \%$ of the regions and the neighbors have the same state transition direction. The number of regions where the region and the neighbor type are simultaneously transferred upwards is 110 , the number with 
downward transfer is 3 , and the number of states that have not transferred is 31 . Therefore, the regional and neighborhood CEI state transfer show synergy, with most having a coordinated upward transfer.

From this analysis, we conclude there is a spatial spillover effect on the CEI based on the regional background, and the type of spatial spillover has important significance. To test the statistical significance of this spatial spillover, a hypothesis test is required. The original assumption is that the types of CEI in the region are independent, regardless of the type of spatial lag. The model formula for the specific test is as follows:

$$
S_{b}=-2 \log \left\{\prod_{l=1}^{k} \prod_{i=1}^{k} \prod_{j=1}^{k}\left[\frac{m_{i j}}{m_{i j}(l)}\right]^{n_{i j}(l)}\right\}
$$

where, $k$ is the CEI type; $m_{i j}$ is the traditional Markov transition probability, $m_{i j}(l)$ and $n_{i j}(l)$ represent the spatial Markov transition probability of the spatial lag type 1 and the corresponding number of cities; and $S_{b}$ obeys the chi-square distribution with a degree of freedom of $k(k-1)^{2}$.

In the case where the degree of freedom is not adjusted, i.e., the element with a zero in the transition probability matrix throughout the study period is excluded, the degree of freedom is $4 \times(4-1)^{2}=36$. From this formula, under the confidence level of $\alpha=0.005$, $S_{b}=93.76>\chi^{2}(40)=66.77$. Therefore, we reject the assumption that China's urban CEI class transfer is independent in space during the 1992-2013 period, and that there is a significant spatial correlation between the type of CEI and the type of state in the field.

Energy intensity is an important indicator of regional socioeconomic development, which has strong energy dependence; therefore, the spatial spillover effect pattern for energy intensity has important significance. The spatial Markov chain analyses show that the CEI in Chinese cities has significant spatial spillover effect and regional synergy. The spatial spillover effect shows two patterns: when in the high CEI region, the probability of rising local CEI increases, while in the low CEI region, the probability of a decline in local CEI increases. The results further illustrate the spatial correlation and spatial interaction of regional energy intensity. The regional synergy shows that the change in energy intensity in the region tends to be consistent, and a coordinated change of regional economic development leads to a coordinated change of energy consumption within the region. Concurrently, differing development patterns between regions show different energy needs and intensities.

Regional economic development is a complex system formed by the interaction of labor, capital, technology, and other elements in specific systems, resources, cultures, and other geographical environments (Zeng et al., 2015). Therefore, development has regional differences and intra-regional similarities. During marketization, the flow of factors between regions has caused various spillover effects, while payment transfers and technology diffusion have caused polarization and spillovers in China's regional economic development (Long, 2003). The market potential theory of new economic geography points out that areas with high economic level and rapid development have great demand for products in surrounding areas, leading to a strong driving effect on them (Pan, 2012), and economic spillover effects make the energy demand between regions more spatially dependent. Moreover, transportation infrastructure is characterized by regional externality, with the network connecting many regions into one, which reduces the cost of factor flow (Zhang, 2012) and promotes 
the flow of inter-regional factors. More frequent factor flows require more energy to support but flows such as labor and capital strengthen the correlation in energy demand between regions. According to the first law of geography, the spatial correlation and dependence of local development are more manifested within the region. Under the conditions of the internal factor flow and improved interconnection infrastructure construction, the regional internal economic development pattern has gradually converged. In addition, technological spillover effects from exogenous and endogenous forces also affect regional energy intensity and characteristics ( $\mathrm{Li}$ and Wang, 2008). The socio-economic activities of the region have complex spatial interaction processes, and patterns in spatial spillover effects of energy intensity are the result of the interaction of various factors, such as economic and institutional factors.

\subsection{Analysis of driving forces of urban CEI}

Although total carbon emissions in China have been increasing in the past two decades (1992-2013), the CEI has shown a downward trend, as the economic growth rate is generally higher than the growth rate of carbon emissions (Li et al., 2010; Zhang, 2010; Cheng et al., 2013). At present, China is in a transitional period of economic growth, dropping from $10.45 \%$ in 2010 to $6.9 \%$ in 2017. In this context, the nation's emission reduction goals face a formidable challenge. The goal of analyzing the driving forces of urban CEI is to identify key factors that promote and reduce the intensity of carbon emissions from the urban level and identify effective measures for different types of cities.

To compare the mean regression coefficients of the traditional panel data model, we first estimated the common fixed effect panel model. In the panel quantile model estimation, five representative points, $10 \%, 25 \%, 50 \%, 75 \%$, and $90 \%$, were selected for estimation, and the total results are shown in Table 5. The panel quantile regression results show the variation in the elastic coefficients of all variables in the urban CEI distribution. We first focus on the impact of urban affluence on urban CEI. In both the mean regression and quantile regression, at a significance level of $1 \%$, the logarithmic primary term for GDP per capita is positive and the secondary term is negative, indicating that there is an inverted "U-shaped" relationship between per capita GDP and CEI. Therefore, the intensity of carbon emissions in cities increases with the increase in per capita GDP. After the per capita GDP reaches a certain level, the CEI will decrease with increasing per capita GDP.

From the regression results, population density and technological progress can significantly reduce urban CEI. Energy is the basic guarantee for the living and production of urban residents, and demographic factors are closely related to urban energy demand. As a key factor in the demographic factor, population density mainly affects the CEI by changing the way people live and behave, with two impacts (Liu et al., 2017; Chai, 2013). First, some cities will benefit from the economies of scale and agglomeration effects of high urban population density, promoting the sharing of urban public service facilities, the formation of knowledge spillovers, labor pools, and specialized intermediates to enhance urban productivity and reduce energy consumption. However, too high an urban population density creates the problem of uneconomical agglomeration. Overcrowding leads to rising competition costs, traffic congestion, and excessive construction, operation and maintenance costs for excessive infrastructure demand (Cai and Sun, 2013; Chen and Yang, 2007). From the empirical results presented in this study, the population density has a significant negative effect 
on CEI and there is no clear uneconomical agglomeration phenomenon. The absolute value of the estimated coefficients for each quantile of population density is greater than the mean regression coefficient, indicating that the mean regression has a tendency to exaggerate the negative influence. As the quantile changes, there is a significant difference in the population density estimation coefficient. The absolute value of the quantile coefficient greater than $50 \%$ is significantly larger than the absolute value of the estimated coefficient for the first $50 \%$ quantile, and the estimated coefficient varies from -0.0813 for the $75 \%$ quantile to -0.0665 for the $10 \%$ quantile. The compact emission reduction effect from population is clear for cities with high CEI; for cities with lower CEI, appropriately increasing population density is not the preferred emission reduction measure.

Table 5 Fixed effect and quantile regression estimates

\begin{tabular}{|c|c|c|c|c|c|c|}
\hline \multirow{2}{*}{ Variables } & $(1)$ & (2) & (3) & (4) & (5) & (6) \\
\hline & FE & q10 & q25 & q50 & q75 & q90 \\
\hline \multirow[t]{2}{*}{ A } & $2.138 * * *$ & $1.5515 * * *$ & $1.6227 * * *$ & $1.6329 * * *$ & $1.4469 * * *$ & $1.2669 * * *$ \\
\hline & $(8.85)$ & (4.97) & $(5.58)$ & $(5.97)$ & $(5.16)$ & $(5.08)$ \\
\hline \multirow[t]{2}{*}{ SA } & $-0.140 * * *$ & $-0.1018^{* * *}$ & $-0.1066^{* * *}$ & $-0.1102 * * *$ & $-0.1071 * * *$ & $-0.1023^{* * *}$ \\
\hline & $(-10.60)$ & $(-5.69)$ & $(-6.14)$ & $(-6.49)$ & $(-6.15)$ & $(-7.07)$ \\
\hline \multirow[t]{2}{*}{$\mathrm{P}$} & $-0.210 * * *$ & $-0.0665 * *$ & $-0.0747 * * *$ & $-0.0792 * * *$ & $-0.0813 * * *$ & $-0.0771 * * *$ \\
\hline & $(-2.76)$ & $(-2.42)$ & $(-2.65)$ & $(-2.89)$ & $(-2.97)$ & $(-2.81)$ \\
\hline \multirow[t]{2}{*}{ IS } & $0.369 * * *$ & $0.1758 * *$ & $0.1963 * *$ & $0.3458 * * *$ & $0.4681 * * *$ & $0.4350 * * *$ \\
\hline & $(3.21)$ & $(2.25)$ & $(2.16)$ & $(2.85)$ & $(4.88)$ & $(5.22)$ \\
\hline \multirow[t]{2}{*}{$\mathrm{CI}$} & 0.159 & $0.0982 * *$ & 0.0954 & 0.1408 & $0.2881 * *$ & $0.4066^{* * *}$ \\
\hline & $(1.65)$ & $(2.42)$ & $(1.36)$ & (1.46) & $(2.53)$ & $(3.34)$ \\
\hline \multirow[t]{2}{*}{ FDI } & $5.427 * *$ & $8.6024 * * *$ & $7.7062 * * *$ & $6.3488 * * *$ & $4.9094 * * *$ & $3.3846 * * *$ \\
\hline & (1.99) & $(5.15)$ & $(4.85)$ & (4.09) & $(3.84)$ & $(3.03)$ \\
\hline \multirow[t]{2}{*}{$\mathrm{T}$} & $-0.0221 * * *$ & $-0.2610 * * *$ & $-0.2528 * * *$ & $-0.2087 * * *$ & -0.0922 & -0.0182 \\
\hline & $(-4.80)$ & $(-4.48)$ & $(-3.68)$ & $(-2.71)$ & $(-1.12)$ & $(-0.41)$ \\
\hline \multirow[t]{2}{*}{ UB } & $0.0426^{* * *}$ & $0.0347 * * *$ & $0.0377 * * *$ & $0.0474 * * *$ & $0.0672 * * *$ & $0.0836^{* * *}$ \\
\hline & (4.79) & $(4.77)$ & (4.9) & (5.4) & $(5.98)$ & $(6.77)$ \\
\hline \multirow[t]{2}{*}{ ROD } & $0.0435 * * *$ & $0.0301 * * *$ & $0.0248 * * *$ & $0.0187 * * *$ & 0.0092 & 0.00349 \\
\hline & $(6.04)$ & $(3.17)$ & $(3.06)$ & (2.64) & $(1.42)$ & $(0.65)$ \\
\hline \multirow[t]{2}{*}{ Cons } & $-6.114 * * *$ & $-4.4682 * * *$ & $-4.5841 * * *$ & $-4.3932 * * *$ & $-3.0907 * *$ & $-1.9161 *$ \\
\hline & $(-4.91)$ & $(-3.14)$ & $(-3.58)$ & $(-3.76)$ & $(-2.54)$ & $(-1.71)$ \\
\hline$N$ & 6226 & 6226 & 6226 & 6226 & 6226 & 6226 \\
\hline
\end{tabular}

Note: The $t$ statistic is represented in parentheses, ${ }^{*} p<0.1,{ }^{*} p<0.05, * * * p<0.01$

In general, technological progress reduces energy intensity by increasing energy efficiency, that is, consuming less energy for the same GDP. However, technological progress 
has both positive and negative effects on energy consumption. While technological progress can improve energy efficiency, at the same time, the return effect means that technological progress stimulates economic activity and increase energy consumption, thereby offsetting energy savings due to efficiency gains. In addition, due to the threshold and time lag effect for technological progress ( $\mathrm{Li}$ and $\mathrm{Zhou}, 2006$; $\mathrm{Li}$ and $\mathrm{Qu}, 2012$ ), in less developed areas, the emission reduction effect from technological progress may not be reflected. The empirical results presented in this study show that technological progress has a negative effect on CEI, and the negative effect of technological progress under high quantile ( $75 \%$ and $90 \%)$ is not significant, while other quantiles at the $1 \%$ confidence level show a significant negative effect. The absolute value of the estimated coefficient increases as the quantile decreases, and the negative effect of technological advancement reaches a maximum at the $10 \%$ quantile. Therefore, technological progress is the main emission reduction factor in areas with low CEI. The energy saved by technological progress is greater than the energy demand increased by economic growth. In areas with high CEI, the contribution of technological progress to emission reductions is not significant.

Factors including industrial structure, investment intensity, foreign capital intensity, urbanization, and road density have contributed to the increase in urban CEI. Prior work suggests that one of the driving forces for China's carbon emission growth comes from industrial structure (Zhang, 2011). In a sample from this study, the number of cities in which the secondary industry added value accounted for more than $50 \%$ of the GDP, approximately $58 \%$ of the total cities in China in 2013, and China's urban industrial structure is still dominated by the secondary, tertiary, and then primary industries. Furthermore, the internal structure of the secondary industry is also unreasonable, with high energy consumption, high emissions, low efficiency, and strong energy dependence (Zheng and Liu, 2011). Because estimated coefficients show significant positive values in both mean regression and quantile, the proportion of the secondary industry is an important factor leading to an increase in urban CEI in China. For different CEI condition quantiles, the estimation coefficient decreases with the decrease of the quantile point, which indicates that the secondary industry has a stronger promotion effect in areas with high CEI. Because most regions with high CEI are still in the stage of rapid industrialization, coal-led energy structure and extensive industrial development patterns have increased energy consumption. Regions with relatively low CEI are mostly economically developed regions. Environmental regulation, industrial transfer, and upgrading have generally improved the energy efficiency of the secondary industry (Xiao et al., 2014; Zhao and Qiu, 2014).

The intensity of investment also promotes the growth of carbon emissions. The estimated coefficient increases with the increase in the quantile, but it is not significant at the mean return and $25 \%$ and $50 \%$ quantile points. In areas with high CEI, investment-driven extensive economic development is one reason for the increase in carbon emissions (Guo, 2010).

The relationship between foreign investment and energy consumption in the literature has generally been discussed in conjunction with the "Pollution Haven Hypothesis" and "Pollution Halo Hypothesis". The "Pollution Haven Hypothesis" is that FDI has transferred high-energy and high-pollution industries, which has led to an increase in carbon emissions to the host country. The "Pollution Halo Hypothesis" is that under domestic environmental regulation, FDI raises the technical level of the host country through knowledge and technology spillovers, which improve energy efficiency and reduce energy intensity. The em- 
pirical results from this study support the "Pollution Haven Hypothesis". From the perspective of city level, the intensity of foreign investment has a significant positive effect on the intensity of carbon emissions. In terms of different conditional quantile levels, foreign investment intensity shows a stronger promotion effect on areas with low CEI. One possible explanation is that most regions with high CEI are those with relatively low economic and technical development. The emission reduction effect brought by FDI technology spillover offsets some of the increased energy consumption; low CEI, due to the high competitive pressure of FDI companies, has hindered the technology spillover of FDI (Li and Liu, 2011).

China's urbanization is accompanied by urban land expansion and utilization type transformation, which has changed the urban carbon sink and carbon cycle process. Concurrently, urban land development, including infrastructure and building construction, will also bring subsequent energy needs (Zhao et al., 2009). Our empirical results show that land urbanization has a significant positive role in CEI, and the estimation coefficient increases with increases in the conditional quantile. In areas with high CEI, the positive effect of land urbanization reaches a maximum, showing that local governments relying on land finance and urbanization of extensive and contagious land development have brought enormous pressure on urban emission reduction (Tian, 2011).

A reasonable urban structure can reduce traffic congestion and improve traffic efficiency, thereby reducing emissions. However, our empirical results show that excluding the $75 \%$ and $90 \%$ conditional quantile levels, which are insignificant, road density plays a significant positive role in the CEI at a confidence level of $1 \%$. These results are supported by existing literature (She et al., 2015). The estimated coefficient decreases with the decrease in quantile, indicating that the effect of road density is stronger in areas with lower CEI. One possible explanation is that transportation has become an important factor in increasing energy consumption in areas with low CEI (Pan et al., 2010). That is, the increase in road density in low CEI areas has improved urban accessibility, spurred demand for transportation, and increased energy consumption in the transportation sector (Park, 2014).

The heterogeneity of urban CEI driving forces is mainly affected by two factors. From the vertical perspective, the main driving forces of CEI vary at different stages of urban development. From the horizontal perspective, differences in urban development patterns will also cause differences in CEI driving forces. In the early and middle stages of urbanization, industrialization and urbanization are rapid with city expansion and development from the investment of a large amount of capital; the relatively primary industrial structure and extensive growth increase energy consumption. From the middle and late stages of urbanization, the speed of urbanization and industrialization slow down and the industrial structure becomes gradually optimized, which improves the city's functions and attracts foreign investment. Under the combined effect of FDI technology spillovers and internal and external factors accumulated by local technology, energy efficiency gradually increases. However, due to the improvement of the traffic network and demand for economic development, the mobility between the elements increases, resulting in an increase in energy consumption in the transportation sector. In addition, the city's development pattern also significantly affects the city's CEI. For example, resource-based cities in Shaanxi, Shanxi, Inner Mongolia, and Heilongjiang rely on the development and utilization of resources to form an industrial cluster with high energy consumption and high emissions. Therefore, the industrial structure of these cities is still the main factor in carbon emissions. In more developed cities along the 
eastern coast, the rising proportion of service industries, industrial transfer, and upgrades have reduced the energy consumption of industrial structures.

This analysis shows that for cities with low CEI, economic growth and technological progress are key measures to reduce carbon emissions. In addition, appropriate population density and compact urban development patterns can also reduce emissions, while foreign investment intensity and traffic emissions are the main factors that increase CEI. For cities with high CEI, focusing on the development of compact cities, appropriately increasing population density, and exerting population size and agglomeration effects are important means of reducing emissions, while industrial emissions, extensive capital investment, and urban land spread are the main factors promoting CEI.

\section{Discussion and conclusions}

This study uses the kernel density estimation method and the spatial autocorrelation method to derive the temporal and spatial evolution pattern of CEI in 283 cities in China for the 1992-2013 period. The kernel density estimation results show that the overall CEI for cities decreased and the difference narrowed. In addition, the distribution of urban CEI does not follow a normal distribution, and the information contained at both ends of the distribution cannot be expressed by mean regression. Therefore, the quantile regression method is a better choice for exploring the driving forces of CEI. The spatial autocorrelation Moran's I index indicates that there has been a significant spatial agglomeration of urban CEI that gradually increased, but differences between regions tend to be stable.

The spatial dynamic analysis process based on the Markov chain and spatial Markov chain shows that there is a Matthew effect in China's urban CEI, and both low-intensity and high-intensity cities have shown a maintenance in the dynamic transfer process for neighboring years. Moreover, a "spatial spillover" effect in urban carbon emissions is clear. There are heterogeneity characteristics of spillover effects in different regional contexts, wherein low CEI neighbors can effectively increase the probability of CEI transferring upwards and vice versa. In addition, we find a trend in the regional convergence for urban CEI, and more than half the regions have the same dynamic direction of urban and regional backgrounds in adjacent years.

To further explore the mechanisms driving urban CEI, we used the quantile regression method to evaluate economic development, population density, industrial structure, capital investment intensity, foreign capital intensity, technological progress, land urbanization, and road density. We find that urban economic development level, population density, and technological progress are conducive to reducing urban CEI, while industrial structure, capital investment intensity, foreign investment intensity, land urbanization, and road density increase urban CEI. In cities with low CEI, economic growth and technological progress are key factors for reducing emissions. Appropriate population density and compact urban development patterns can also reduce emissions; while foreign investment intensity and traffic emissions are the main factors in increasing carbon emissions. In cities with high CEI, focusing on the development of compact cities, appropriately increasing population density, and exerting population size and agglomeration effects are important means of reducing emissions; industrial emissions, extensive capital investment, and urban land expansions are the main factors in increasing CEI. We propose that in areas with low CEI, foreign investment should be directed to low-energy, low-pollution, high-efficiency, high-tech industries, 
while at the same time exerting the knowledge spillover effect brought by foreign investment. Furthermore, focusing on road traffic energy consumption, improving transportation structure, and developing transportation energy-saving technologies can be used to achieve emission reduction goals. For regions with high CEI, optimizing industrial structure and improving capital utilization efficiency are key to further reducing CEI. However, local governments should diminish the disorderly expansion of cities due to excessive dependence on land finance.

More generally, this study finds that the spatial Markov chain method can effectively measure the spatial and temporal evolution process and patterns of CEI in cities and regions, and intuitively reveal the heterogeneity and regional characteristics of the "space spillover" effect of CEI. This method narrows the evolution scale to adjacent years, shows the continuing process of regional CEI evolution, and highlights regional transfer trends in the context of the neighborhood. In addition, the scale of research at the urban level can better explain the heterogeneity of urban development within provinces and the convergence of provincial junctions, providing a scientific basis for governments to formulate emission reduction strategies for different cities. Quantile regression analysis is an important mechanism for exploring driving forces that can identify more comprehensive explanations for CEI. This method emphasizes the heterogeneity of driving forces in the context of different CEI, thus avoiding the idealized mean regression model. The results of this research better reflect true conditions, and as such can be used to formulate targeted policy measures for various cities across the country.

\section{References}

Cai B F, Cao D, Liu L C et al., 2011. China transport $\mathrm{CO}_{2}$ emission study. Advances in Climate Change Research, 7(3): 197-203. (in Chinese)

Cai Y Y, Sun B D, 2013. Spatial dispersion of population and economic growth: Based on empirical analysis of megacities. Urban Insight, 27(5): 94-101. (in Chinese)

Chai Z X, 2013. Density effects, development level and China's urban carbon dioxide emission. On Economic Problems, (3): 25-31. (in Chinese)

Chen L W, Yang K Z, 2007. Productivity, urban scale and economic density: An empirical study on the economic effect of urban agglomeration. Social Sciences in Guizhou, (2): 113-119. (in Chinese)

Chen P Y, Zhu X G, 2013. Regional convergence at county level in China. Scientia Geographica Sinica, 33(11): 1302-1308. (in Chinese)

Chen Q, 2010. Advanced Econometrics and Stata Application. Beijing: Higher Education Press. (in Chinese)

Cheng Y Q, Zhang S Z, Ye X Y et al., 2013. Spatial econometric analysis of CEI and its driving factors from energy consumption in China. Acta Geographica Sinica, 68(10): 1418-1431. (in Chinese)

Cong J H, Liu X M, Zhao X R, 2014. Demarcation problems and the corresponding measurement methods of the urban carbon accounting. China Population, Resources and Environment, 24(4): 19-26. (in Chinese)

Dong F, Yu B L, Hadachin T et al., 2018. Drivers of CEI change in China. Resources, Conservation and Recycling, 129: 187-201.

Gallo J L, 2004. Space-time analysis of GDP disparities among European regions: A Markov chain approach. International Regional Science Review, 27(2): 138-163.

Glaeser E L, Kahn M E, 2010. The greenness of cities: Carbon dioxide emissions and urban development. Journal of Urban Economics, 67(3): 404-418.

Gu C L, Tan Z B, Liu W et al., 2009. A study on climate change, carbon emissions and low-carbon city planning. Urban Planning Forum, (3): 38-45. (in Chinese)

Guo C X, 2010. An analysis of the increase of $\mathrm{CO}_{2}$ emission in China: Based on SDA technique. China Industrial Economics, (12): 47-56. (in Chinese)

International Energy Agency (IEA), 2010. World Energy Outlook 2009 Factsheet.

Jiao W X, Chen X P, 2012. Environmental impact analysis of Gansu province based on the stirpat model. Re- 
sources and Environment in the Yangtze Basin, 21(1): 105-110. (in Chinese)

Jotzo F, Pezzey J C V, 2007. Optimal intensity targets for greenhouse gas emissions trading under uncertainty. Environmental \& Resource Economics, 38(2): 259-284.

Koenker R, 2004. Quantile regression for longitudinal data. Journal Multivariate Analysis, 91(1): 74-89.

Koenker R, Bassett G, 1978. Regression quantiles. Econometrica, 46(1): 33-50.

Li G Z, Wang S, 2008. Regional factor decompositions in China's energy intensity change: Base on LMDI technique. Journal of Finance and Economics, 34(8): 52-62. (in Chinese)

Li J X, Chen Y N, Li Z et al., 2018. Quantitative analysis of the impact factors of conventional energy carbon emissions in Kazakhstan based on LMDI decomposition and STIRPAT model. Journal of Geographical Sciences, 28(7): 1001-1019.

Li K J, Qu R X, 2012. Impact of technological change on carbon dioxide emission: An empirical analysis based on provincial dynamic panel data model. Journal of Beijing Normal University (Social Sciences), (5): 129-139. (in Chinese)

Li L S, Zhou Y, 2006. Can technological progress improve energy efficiency? Empirical test based on China's industrial sector. Management World, (10): 82-89. (in Chinese)

Li S T, Hou Y Z, Liu Y Z et al., 2004. The analysis on survey of local protection in China domestic market. Economic Research Journal, (11): 78-84. (in Chinese)

Li Y M, Zhang L, Cheng X L, 2010. A decomposition model and reduction approaches for carbon dioxide emissions in China. Resources Science, 32(2): 218-222. (in Chinese)

Li Z H, Liu H H, 2011. FDI, technology progress and emission of $\mathrm{CO}_{2}$ : Evidence from Chinese provincial data. Studies in Science of Science, 29(10): 1495-1503. (in Chinese)

Lin B Q, Huang X G, 2011. Evolution trend of China's regional carbon emission under the gradient development model-Based on the perspective of spatial analysis. Journal of Financial Research, (12): 35-46. (in Chinese)

Liu Y H, Gao C C, Lu Y Y, 2017. The impact of urbanization on GHG emissions in China: The role of population density. Journal of Clean Production, 157: 299-309.

Liu Y H, Ge Q S, He F N et al., 2008. Countermeasures against international pressure of reducing $\mathrm{CO}_{2}$ emissions and analysis on China's potential of $\mathrm{CO}_{2}$ emission reduction. Acta Geographica Sinica, 63(7): 675-682. (in Chinese)

Long G Y, 2003. Understanding China's recent growth experience: A spatial econometric perspective. Annals of Regional Science, 37(4): 613-628.

Luo Y X, Tian M Z, 2010. Quantile regression for panel data and its simulation study. Statistical Research, 27(10): 81-87. (in Chinese)

Ma D L, Chen Z C, Wang L, 2015. Spatial econometrics research on inter-provincial carbon emissions efficiency in China. China Population, Resources and Environment, 25(1): 67-77. (in Chinese)

Pan M, Lv B, Zhang C et al., 2010. Thinking of model system construction of building energy efficiency and green building. Urban Studies, (7): 6-11. (in Chinese)

Pan W Q, 2012. Regional linkage and the spatial spillover effects on regional economic growth in China. Economic Research Journal, (1): 54-65. (in Chinese)

Park J, 2014. The Effects of Compact City Form on Transportation Energy Consumption and Air Pollution. Beijing: Tsinghua University Press. (in Chinese)

Pettersson F, Maddison D, Acar S et al., 2014. Convergence of carbon dioxide emissions: A review of the literature. International Review of Environmental \& Resource Economics, 7(2): 141-178.

She Q N, Jia W X, Pan C et al., 2015. Spatial and temporal variation characteristics of urban forms' impact on regional carbon emissions in the Yangtze River Delta. China Population, Resources and Environment, 25(11): 44-51. (in Chinese)

Su W S, Liu Y Y, Wang S J et al., 2018. Regional inequality, spatial spillover effects, and the factors influencing city-level energy-related carbon emissions in China. Journal of Geographical Sciences, 28(4): 495-513.

Sun Y H, Zhong W Z, Qing D R, 2012. Analysis on differences of CEI of each province in China based on Theil index. Finance and Trade Research, 23(3): 1-7. (in Chinese)

Tian L, 2011. Urbanization of land in urbanization progress of China: Boon or bane? City Planning Review, 35(2): 11-12. (in Chinese)

Wang S J, Fang C L, Guan X L et al., 2014a. Urbanization, energy consumption, and $\mathrm{CO}_{2}$ emissions in China: A panel data analysis of China's province. Applied Energy, 136: 738-749.

Wang S J, Fang C L, Ma H T et al., 2014b. Spatial differences and multi-mechanism of carbon footprint based on GWR model in provincial China. Journal of Geographical Sciences, 24(4): 804-822.

Wang S J, Fang C L, Wang Y, 2016a. Spatiotemporal variations of energy-related $\mathrm{CO}_{2}$ emissions in China and its influencing factors: An empirical analysis based on provincial panel data. Renewable \& Sustainable Energy 
Reviews, 55: 505-515.

Wang S J, Fang C L, Wang Y et al., 2015. Quantifying the relationship between urban development intensity and carbon dioxide emissions using a panel data analysis. Ecological Indicators, 49: 121-131.

Wang S J, Li Q Y, Fang C L et al., 2016b. The relationship between economic growth, energy consumption, and $\mathrm{CO}_{2}$ emissions: Empirical evidence from China. Science of the Total Environment, 542: 360-371.

Wang S J, Liu X P, 2017. China's city-level energy-related $\mathrm{CO}_{2}$ emissions: Spatiotemporal patterns and driving forces. Applied Energy, 200: 204-214.

Wang S J, Liu X P, Zhou C S et al., 2017. Examining the impacts of socioeconomic factors, urban form, and transportation networks on $\mathrm{CO}_{2}$ emissions in China's megacities. Applied Energy, 185: 189-200.

Wang Y, Cheng X, Yin P H et al., 2013. Research on regional characteristics of China's carbon emission performance based on entropy method and cluster analysis. Journal of Natural Resources, 28(7): 1106-1116. (in Chinese)

Wang Z, Ma C F, Wang Y et al., 2003. A geographical investigation into knowledge spillovers between regions. Acta Geographica Sinica, 58(5): 773-780. (in Chinese)

Wu J X, Guo Z Y, 2016. Research on the convergence of carbon dioxide emissions in China: A continuous dynamic distribution approach. Statistical Research, 33(1): 54-60. (in Chinese)

Xiao Y F, Wan Z J, Liu H G, 2014. An empirical study of carbon emission tranfer and carbon leakage in regional industrial transfer in China: Analysis based on inter-regional input-output model in 2002 and 2007. Journal of Finance and Economics, 40(2): 75-84. (in Chinese)

Xie R, Fang J Y, Liu C J, 2017. The effects of transportation infrastructure on urban carbon emissions. Applied Energy, 196: 199-207.

Xu G Y, 2010. The convergence in carbon dioxide emissions: Theoretical hypotheses and empirical research in China. The Journal of Quantitative \& Technical Economics, (9): 31-42. (in Chinese)

Xu J H, 1996. Mathematical Methods in Contemporary Geography. Beijing: Higher Education Press. (in Chinese)

Yan Y M, Wang Z, Wu L Y et al., Analysis of the determinants of CEI on regional differences. Acta Scientiae Circumstantiae, 36(9): 3436-3444. (in Chinese)

York R, Rosa E A, Dietz T, 2003. STIRPAT, IPAT and ImPACT: Analytic tools for unpacking the driving forces of environmental impacts. Ecological Economics, 46(3): 351-365.

Zeng G, Shang Y M, Si Y F, 2015. The convergent evolution of China's regional economic development models. Geographical Research, 34(11): 2005-2020. (in Chinese)

Zhang G Y, 2010. Economic development pattern change impact on China's CEI. Economic Research Journal, (4): 120-133. (in Chinese)

Zhang L F, 2011. Relations among the industry structure, energy structure and carbon emissions. Journal of Arid Land Resources and Environment, 25(5): 1-7. (in Chinese)

Zhang L J, Liu G L, Qin Y C, 2014. Multi-scale integrated assessment of urban energy use and $\mathrm{CO}_{2}$ emissions. Journal of Geographical Sciences, 24(4): 651-668.

Zhang T X, Zeng A Z, 2013. Spatial econometrics analysis on China transport carbon emissions. Urban Development Studies, 20(10): 14-20. (in Chinese)

Zhang X L, 2012. Has transport infrastructure promoted regional economic growth? With an analysis of the spatial spillover effects of transport infrastructure. Social Sciences in China, (3): 60-77. (in Chinese)

Zhao G M, Chen L Z, Sun L C et al., 2017. Markov steady state prediction of CEI in China, based on the perspective of spatial differentiation. Science and Technology Management Research, 37(22): 228-233. (in Chinese)

Zhao Q Z, Yan Q Y, Zhao H R, 2018. Research on spatial characteristics and influencing factors of provincial carbon emissions in China. Journal of Beijing Institute of Technology (Social Sciences Edition), 20(1): 9-16. (in Chinese)

Zhao R Q, Huang X J, Xu H et al., 2009. Progress in the research of carbon cycle and management of urban system. Journal of Natural Resources, (10): 1847-1859. (in Chinese)

Zhao R Y, Qiu Z Z, 2014. Review on the relationship between industrial structure and carbon emission. Economic Review, (10): 110-113. (in Chinese)

Zhao Y T, Huang X J, Zhong T Y et al., 2011. Spatial pattern evolution of CEI from energy consumption in China. Environmental Science, 32(11): 3145-3152. (in Chinese)

Zheng C D, Liu S, 2011. Industrial structure and carbon emission: An empirical analysis based on China provincial panel data. Research on Development, (2): 26-33. (in Chinese)

Zhou J Q, Wang T S, 2014. Convergence of regional economic growth and CEI difference and its mechanism: An empirical analysis based on Chinese provincial panel data. Social Science Research, (5): 66-73. (in Chinese) 